\title{
$\mathbb{N}<\mathrm{IT}$
}

trumbatit

\section{Outgassing Measurements for the ITER EC H\&CD Upper Launcher}

G. Aiello, A. Meier, T. Scherer, S. Schreck, P. Spaeh, D. Strauss, A. Vaccaro

Institute for Applied Materials - Applied Materials Physics
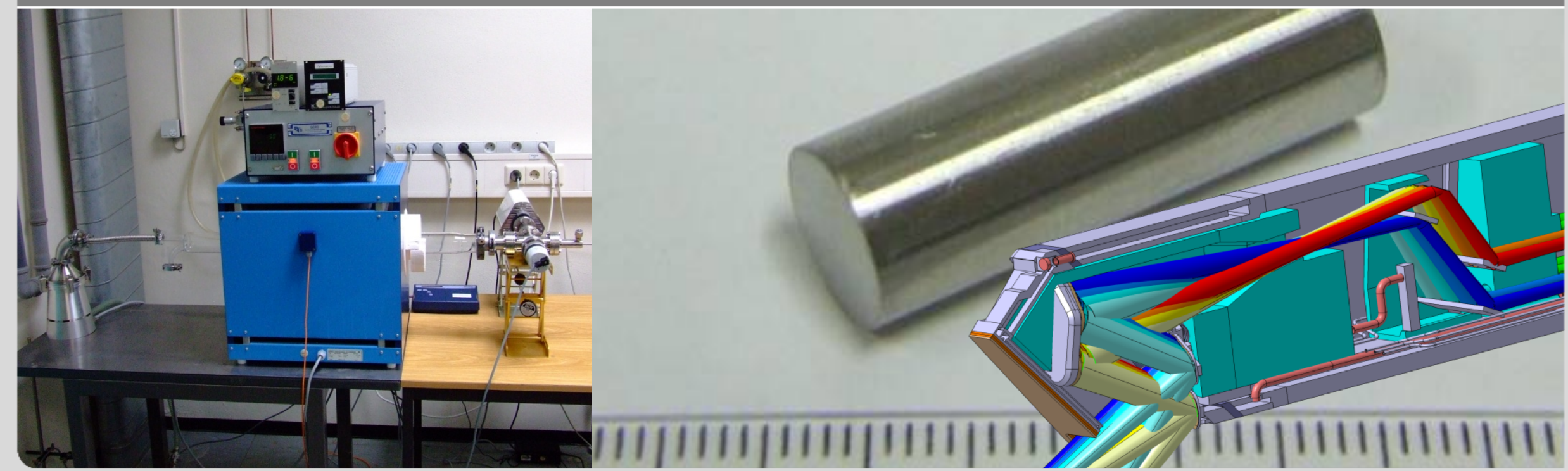


\section{The EC H\&CD Upper Launcher}

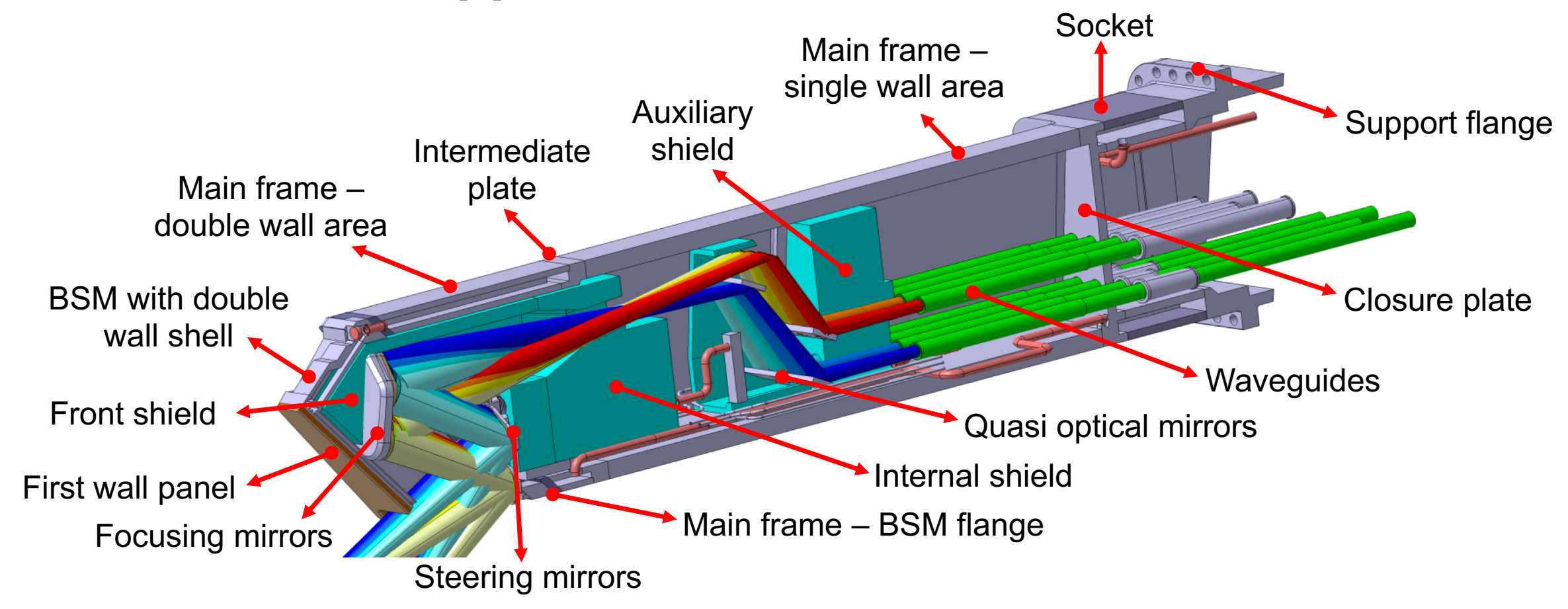

\section{In-vessel component:}

- 316L(N)-IG stainless steel as structural material

- $\mathrm{T}=120-150^{\circ} \mathrm{C}\left(240^{\circ} \mathrm{C}\right.$ for baking $)$

- Internal vacuum $\sim 10^{-3}-10^{-2} \mathrm{~Pa}$ 


\section{Hot Isostatic Pressing (HIPing)}
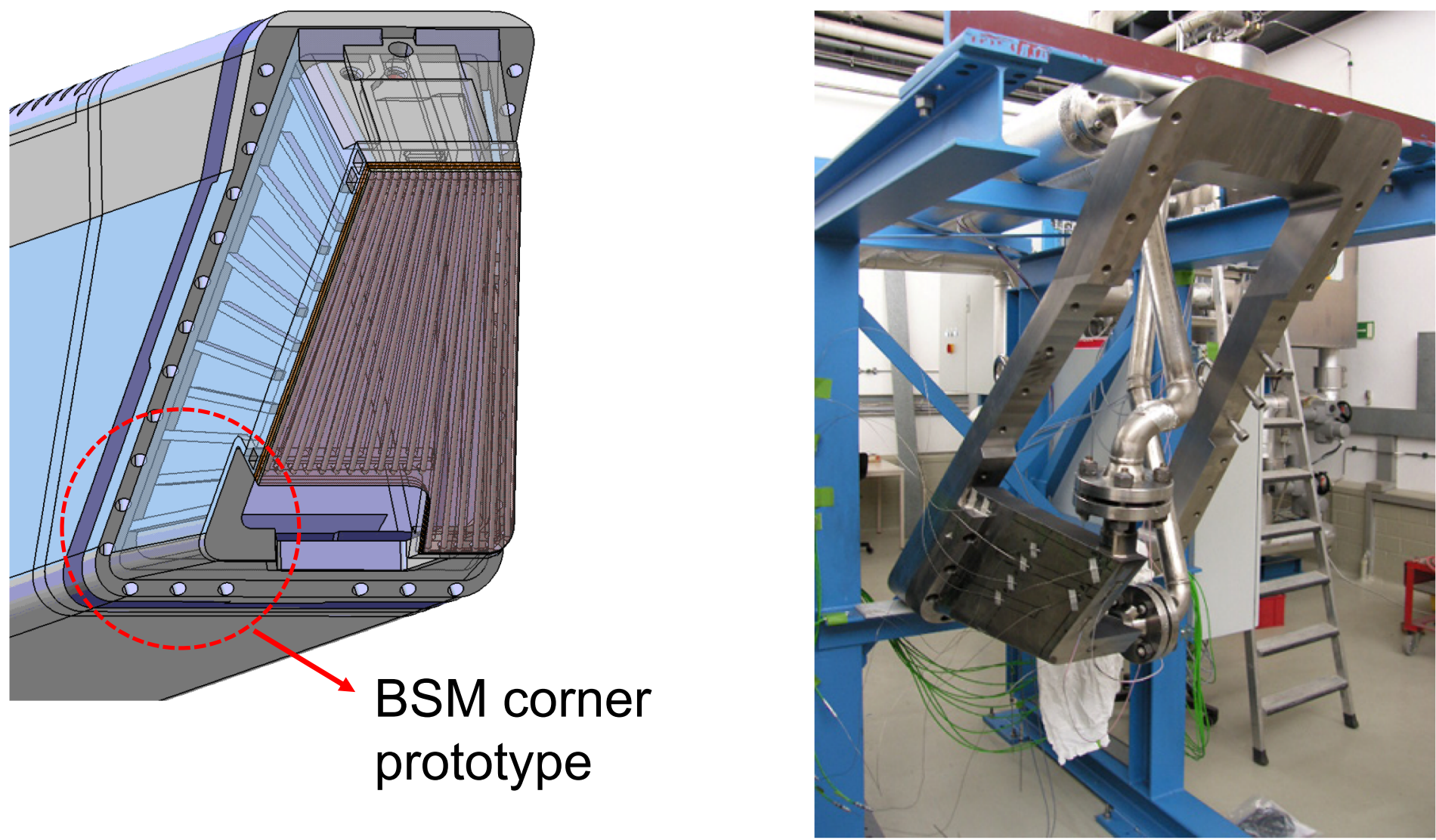

HIPing: one of the preferred manufacturing routes for Upper Launcher (UL) components. 


\section{Outgassing measurements: why?}

ITER Vacuum Handbook:

\begin{tabular}{|c|c|c|c|c|c|}
\hline \multirow{4}{*}{$\begin{array}{l}\text { UL belongs to the } \\
1^{\text {st }} \text { class of the }\end{array}$} & & & & & \\
\hline & \multirow[b]{2}{*}{$\mathrm{VQC}^{+}$} & \multirow[b]{2}{*}{$\begin{array}{c}\text { Outgas } \\
\text { temperature } \\
{ }^{\circ} \mathrm{C}\end{array}$} & \multicolumn{2}{|c|}{$\begin{array}{c}\text { Maximum Steady State } \\
\text { Outgassing rate } \\
\text { Pa. } \mathrm{m}^{3} \cdot \mathrm{s}^{-1} \cdot \mathrm{m}^{-2}\end{array}$} & \multirow[b]{2}{*}{ Testing Guidelines } \\
\hline & & & $\begin{array}{l}\text { Hydrogen } \\
\text { isotopes }\end{array}$ & Impurities & \\
\hline & 1 & $100^{\ddagger}$ & & & Appendix 17 \\
\hline Iaccifination & 2 & 20 & \multicolumn{2}{|c|}{$1 \times 10^{-7^{*}}$} & Appendix 17 \\
\hline 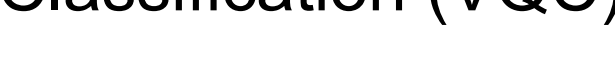 & 3 & 20 & \multicolumn{2}{|c|}{$1 \times 10^{-8}$} & Appendix 17 \\
\hline & 4 & 20 & \multicolumn{2}{|c|}{$1 \times 10^{-7}$} & $\begin{array}{l}\text { Published data and } \\
\text { conformity to clean work } \\
\text { plan. }\end{array}$ \\
\hline
\end{tabular}

No outgassing data in literature for HIPed stainless steel
Experimental measurements are necessary to verify the compliance with the limits 


\section{Measurement technique}

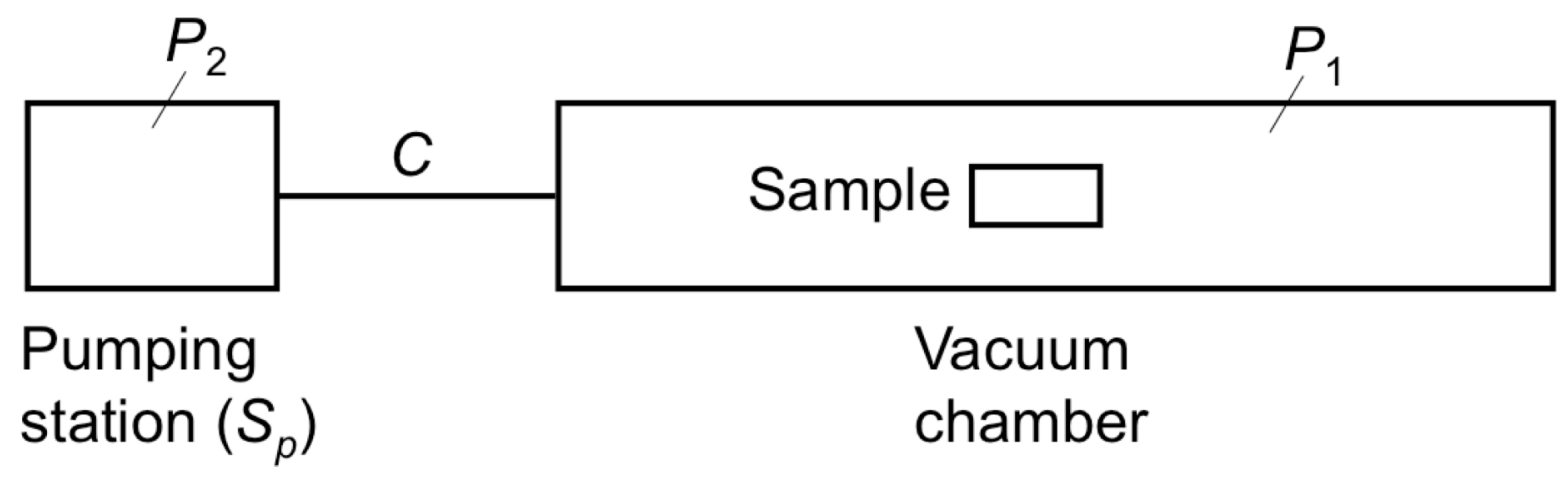

- Conductance method: $Q=C\left(P_{1}-P_{2}\right)$

- Variant of conductance method: $Q=C P_{1} \quad$ (only if $C \ll S_{p}$ )

After blank and sample runs, the specific outgassing rate $q$ of the sample is calculated as

$$
q=\frac{C\left(P_{s R}-P_{b R}\right)}{A_{r}} \quad\left[\mathrm{~Pa} \mathrm{~m}^{3} \mathrm{~s}^{-1} \mathrm{~m}^{-2}\right]
$$

Specific partial

outgassing rates of the sample can be calculated. 


\section{Experimental setup}

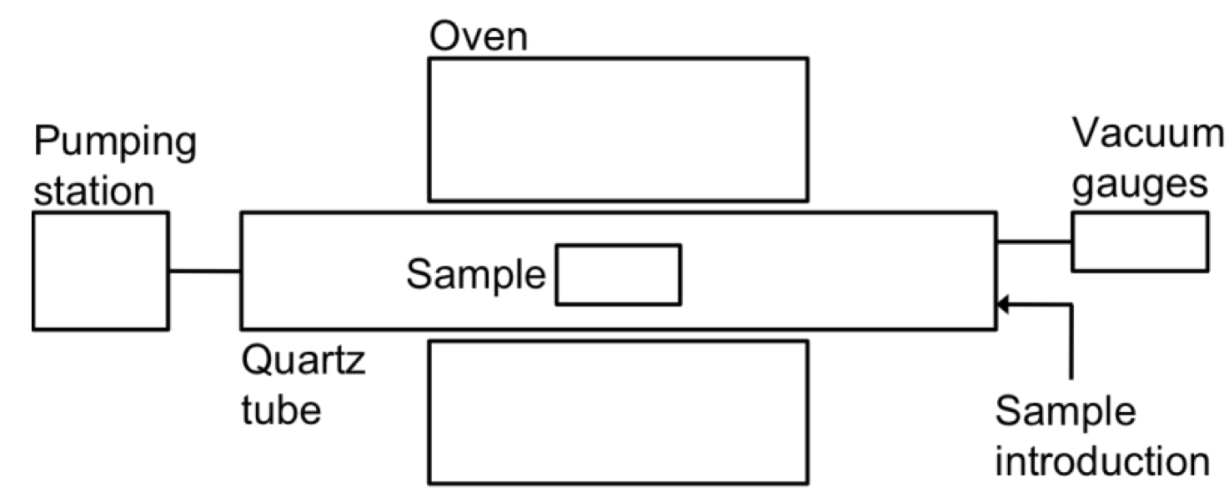

$$
C=\frac{1}{6} \sqrt{\frac{2 \pi R T}{M}} \frac{d^{3}}{l}
$$

For $\mathrm{N}_{2}: S_{p} / C \approx 143$

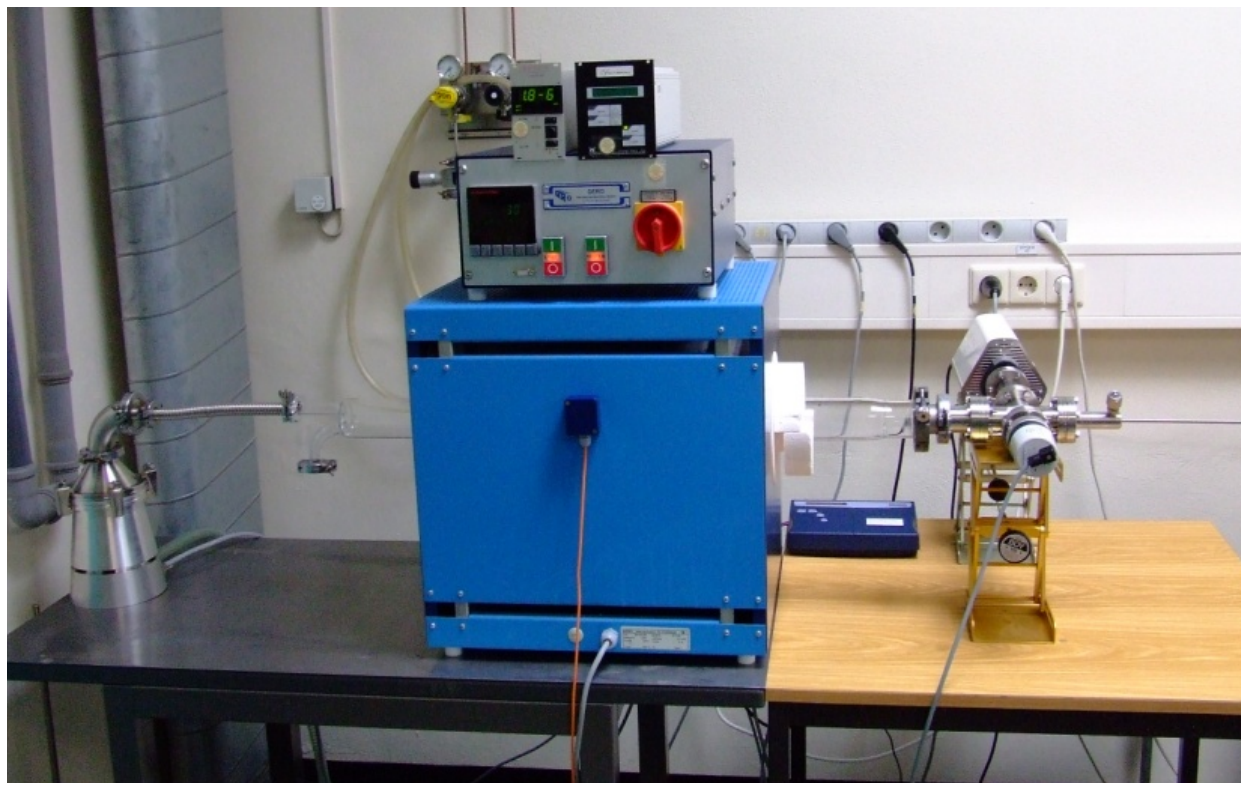

$q$ depends on:

- time

- temperature

- surface finish

- material

- manufacturing process

- etc... 


\section{Stainless steel samples}

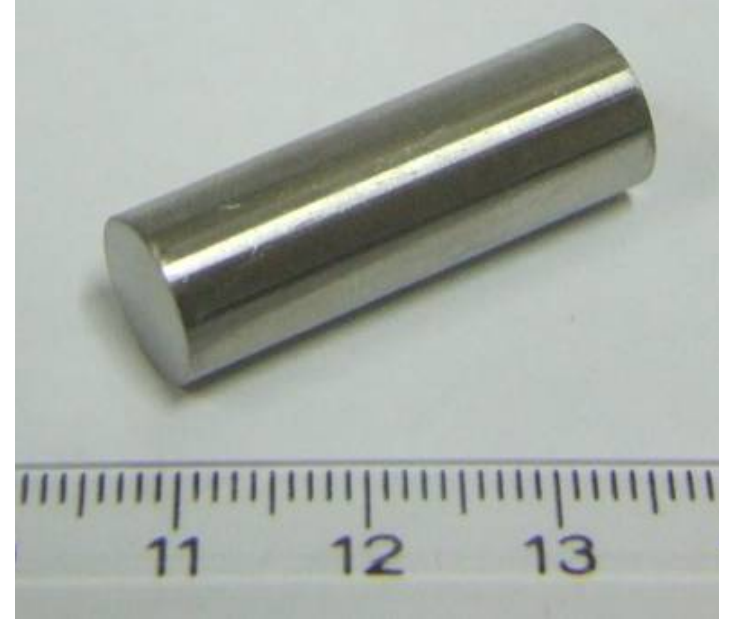

In each pair:
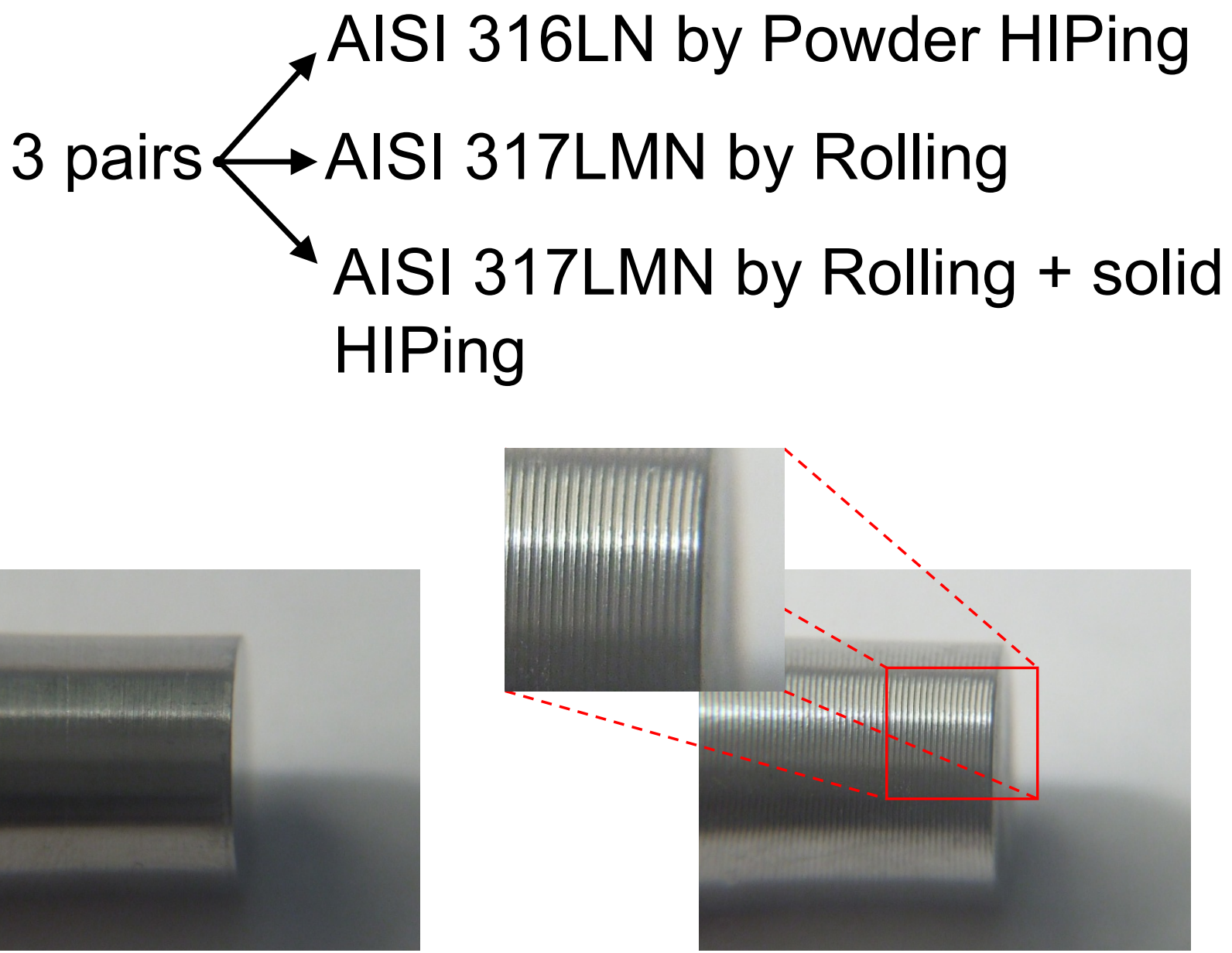

Sample with rills 


\section{Roughness measurements}

Purpose: determination of the surface factor of each sample

$$
f_{s}=\frac{A_{r}}{A_{g}}
$$

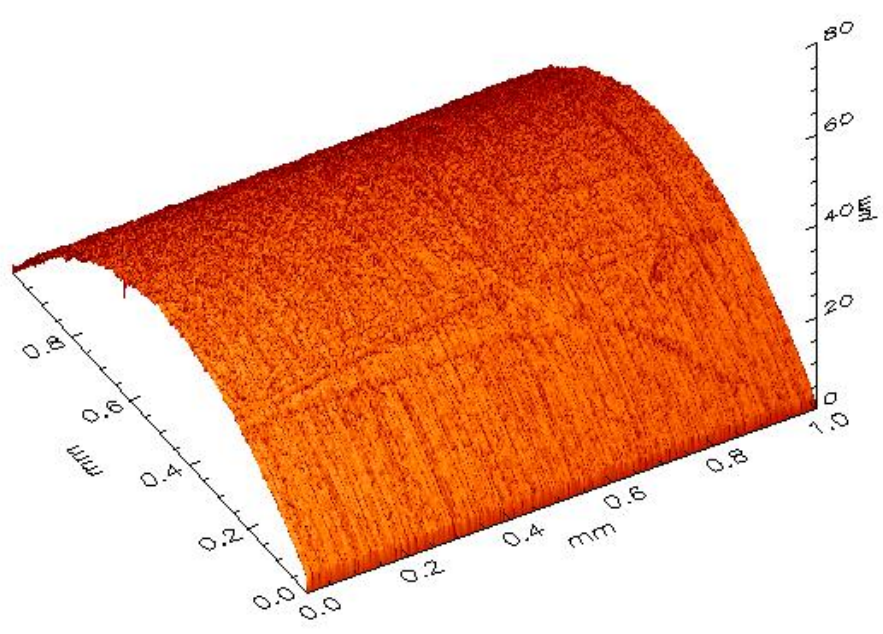

Polished sample

$$
f_{s} \approx 1.2
$$

Raw data related to an area of $1 \mathrm{~mm}^{2}$ obtained by optical method.

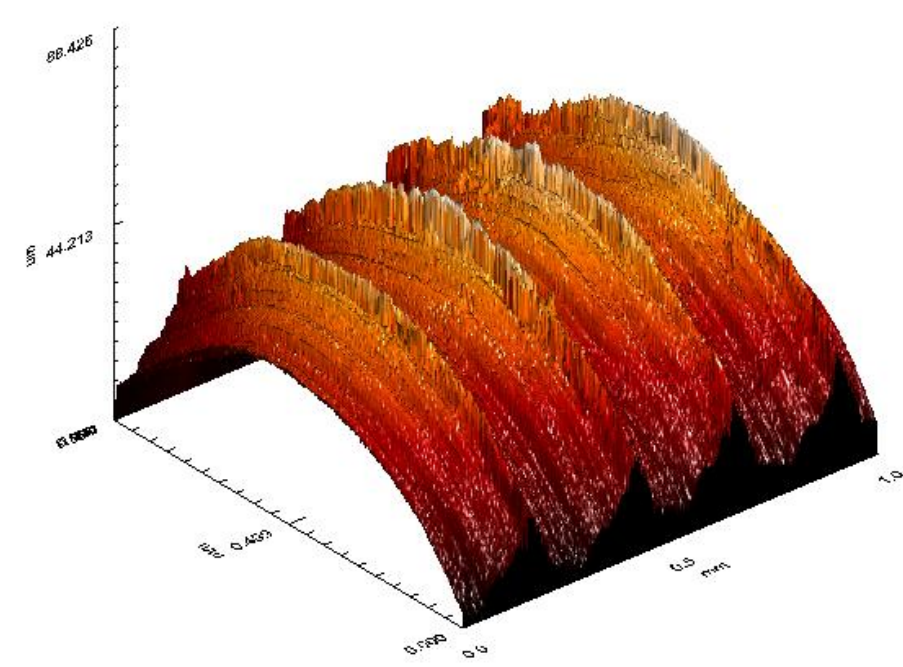

Sample with rills

$f_{s} \approx 1.8$ 


\section{Temperature calibration}
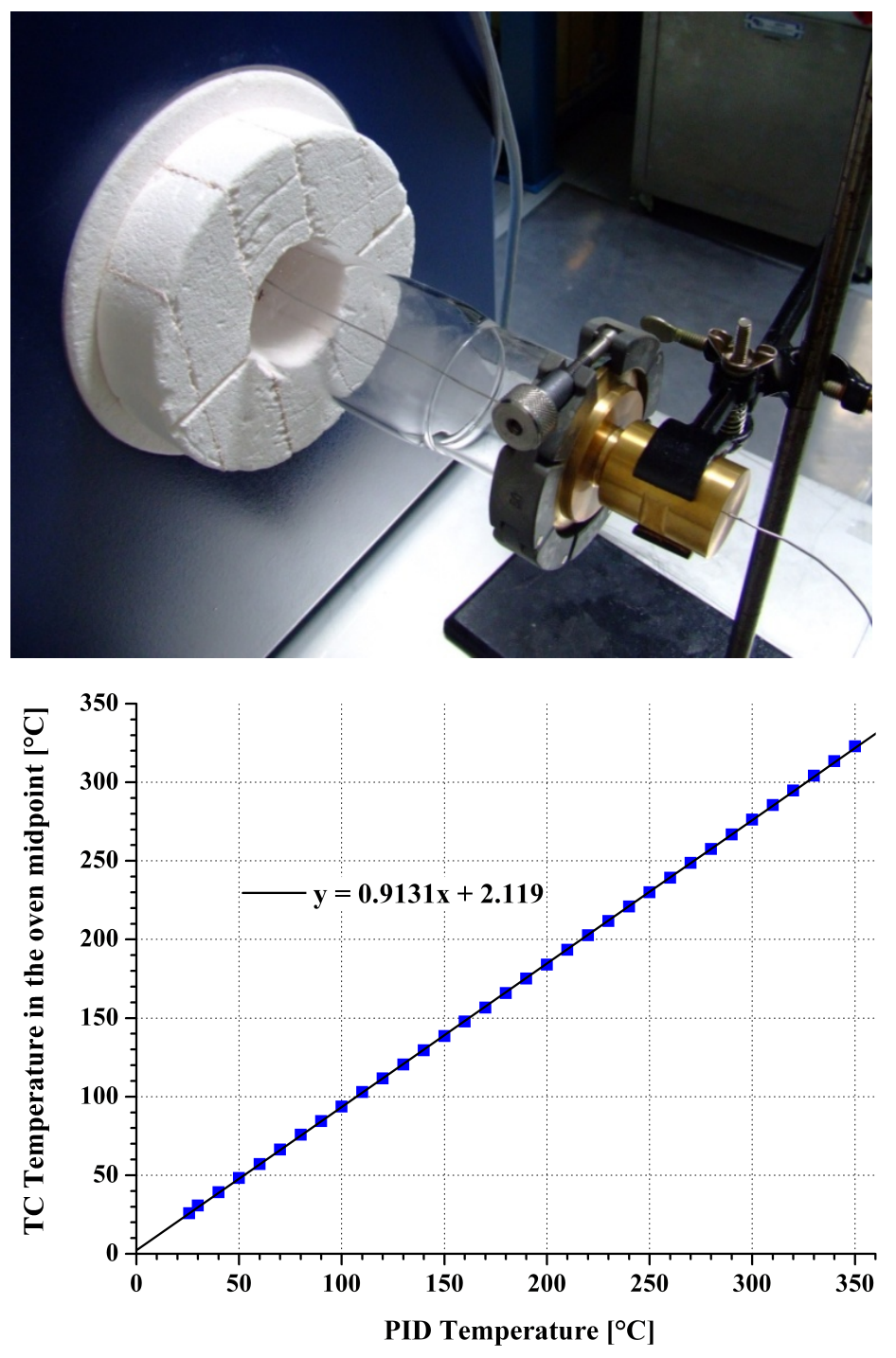

\section{Calibration at pressures of $\sim 10^{-5} \mathrm{~Pa}$ covering the temperature range of interest.}

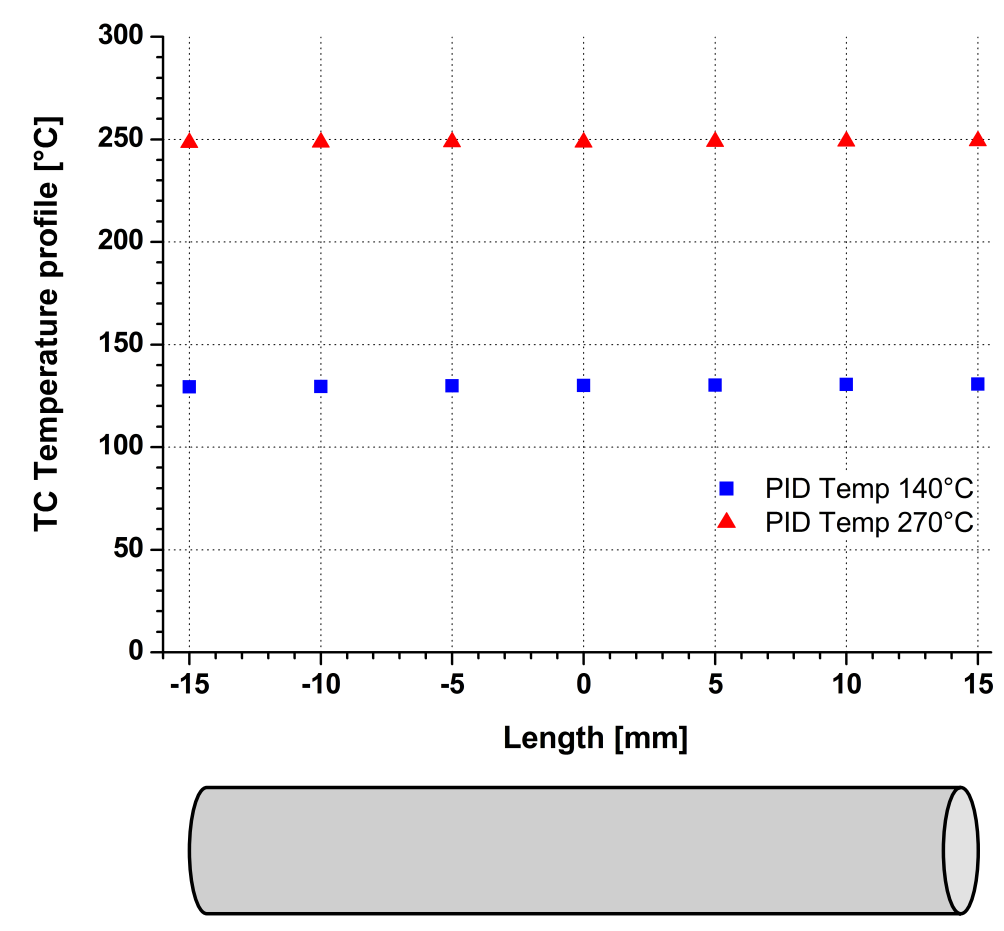




\section{Typical mass spectrum}

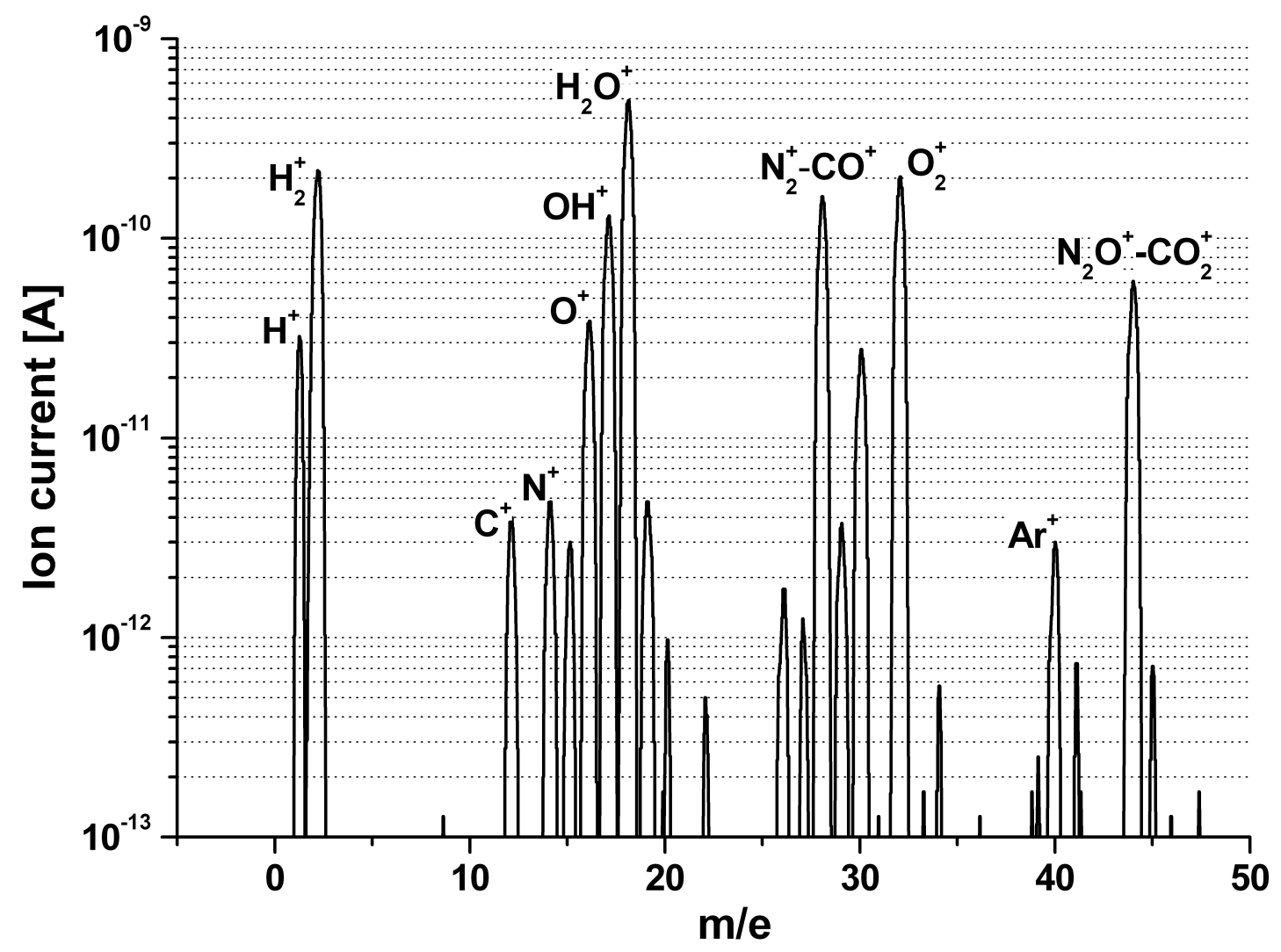

Gas species: $\mathrm{H}_{2}, \mathrm{H}_{2} \mathrm{O}, \mathrm{N}_{2} / \mathrm{CO}, \mathrm{O}_{2}, \mathrm{Ar}, \mathrm{N}_{2} \mathrm{O} / \mathrm{CO}_{2} \ldots$ 


\section{First results - 1}

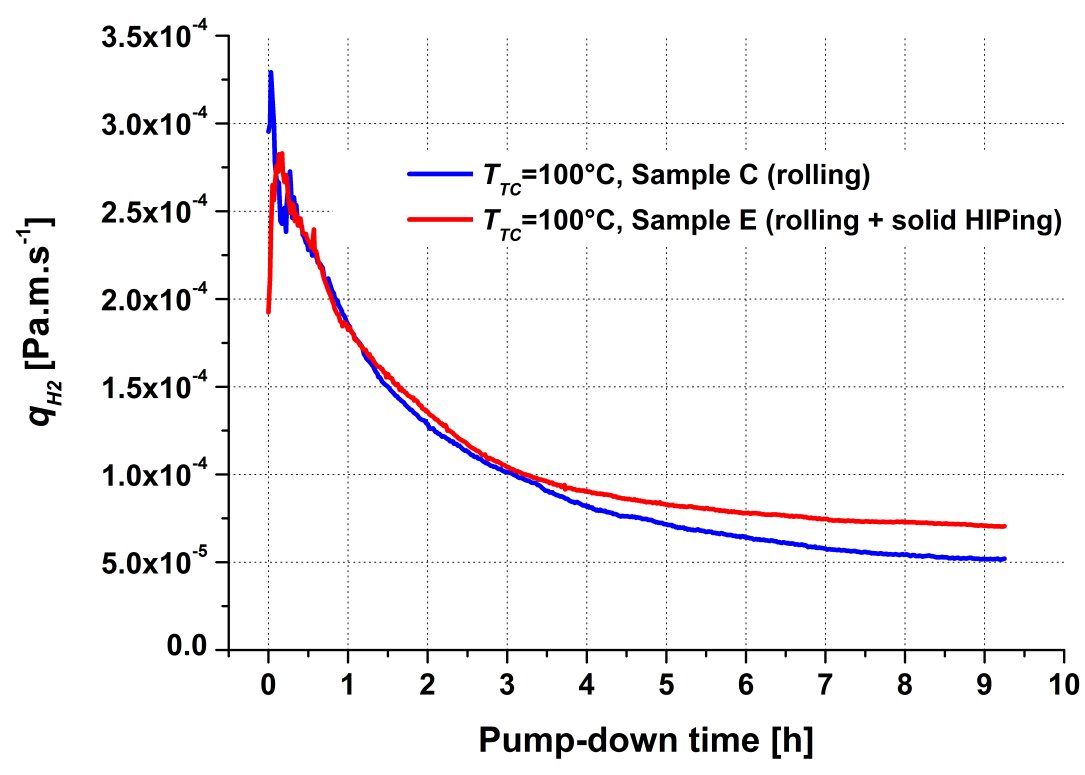

\section{Effect of the solid HIPing}

\section{Effect of the temperature}

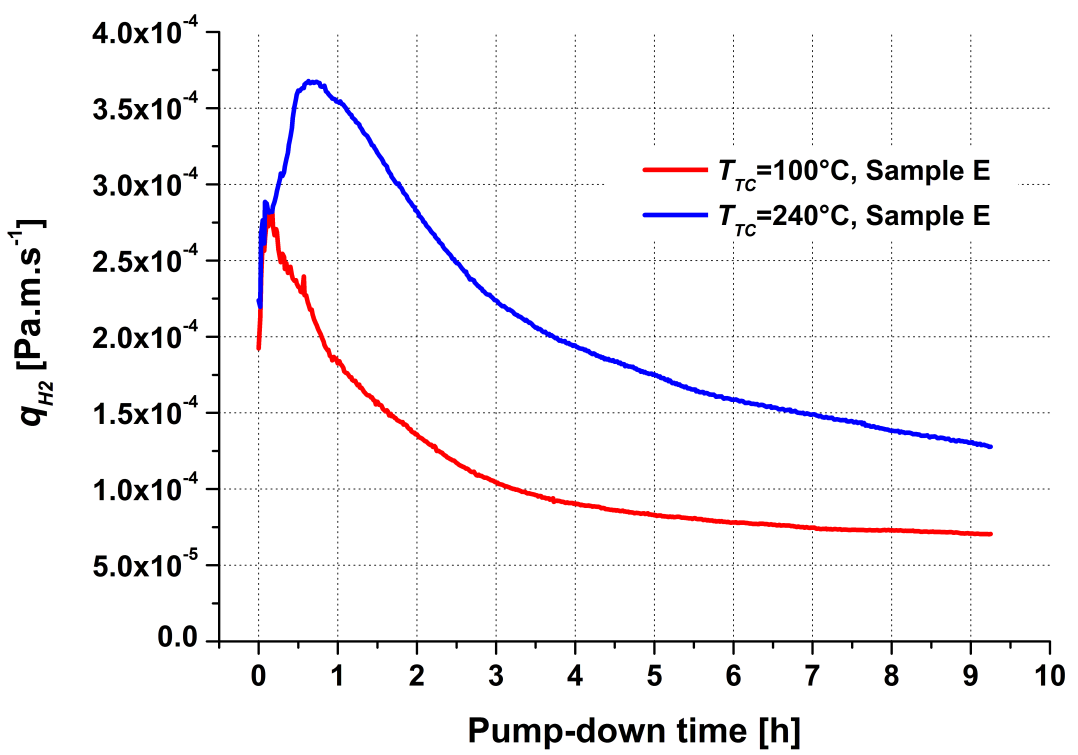




\section{First results - 2}

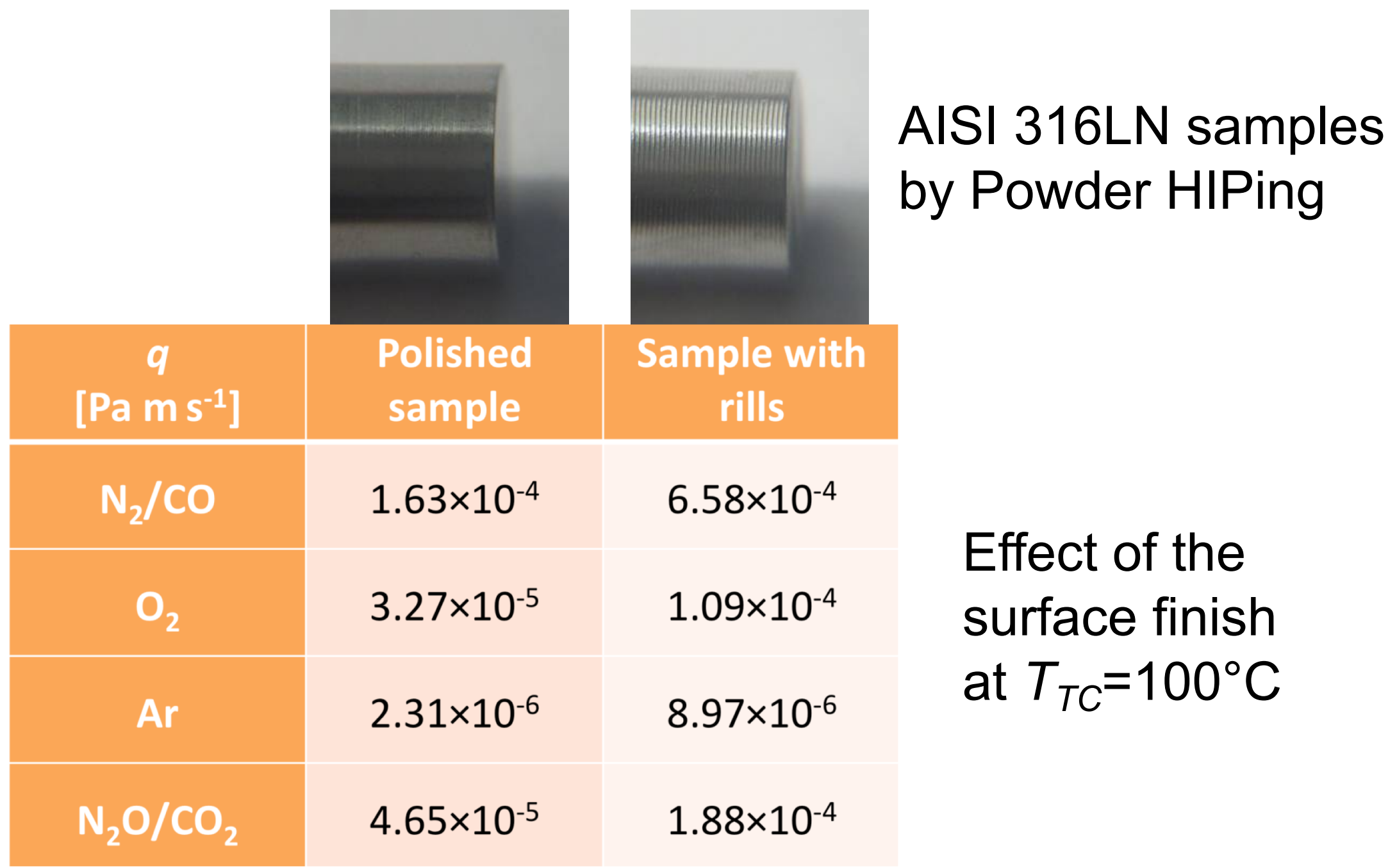




\section{Vacuum baking}

ITER Vacuum Handbook:

\begin{tabular}{|c|c|c|c|}
\hline Vacuum Classification & $\begin{array}{c}\text { Temperature } \\
\left({ }^{\circ} \mathbf{C}\right)\end{array}$ & $\begin{array}{c}\text { Time } \\
(\mathbf{h r})\end{array}$ & Comment \\
\hline VQC 1 & 240 & 24 & \\
\hline VQC 1* & 350 & 24 & Stainless steel and beryllium \\
\hline
\end{tabular}

${ }^{*}$ For vacuum items in line vicinity of plasma

Literature (Elsey, 1975):

\section{0 series SS sample preparation}

\section{Measurement temperature $\left[{ }^{\circ} \mathrm{C}\right]$}

100

100

\begin{abstract}
Vacuum baking for $25 \mathrm{~h}$ at $300^{\circ} \mathrm{C}$

Vacuum baking

for $25 \mathrm{~h}$ at $300^{\circ} \mathrm{C}$
\end{abstract}

Vacuum baking conditions must be consistent with the outgassing limits.

\section{Specific outgassing rate of $\mathrm{H}_{2}\left[\mathrm{~Pa} \mathrm{~m} \mathrm{~s}{ }^{-1}\right]$}

$$
2.8 \times 10^{-7}
$$

$5.9 \times 10^{-8}$ 


\section{Double wall prototype and outgassing - 1}

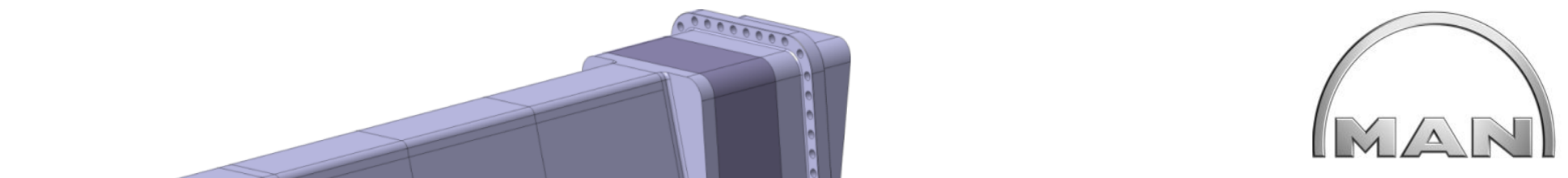

Nuclear heat loads up to $0.8 \mathrm{~W} \mathrm{~cm}^{-3}$
MAN DWE Apparatebau

Deggendorf www.man-dwe.de

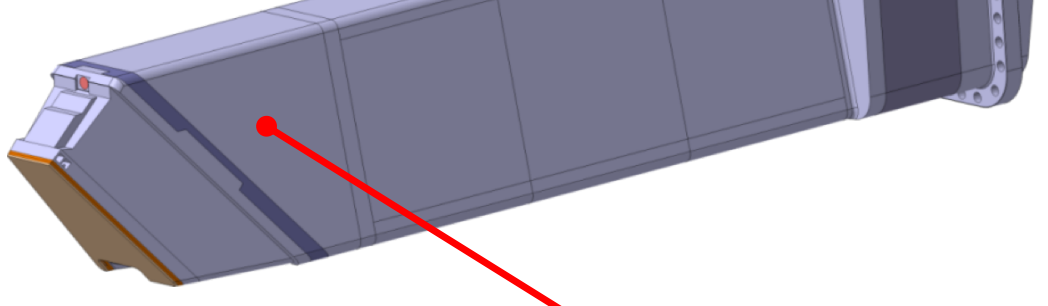

2 manufacturing options:
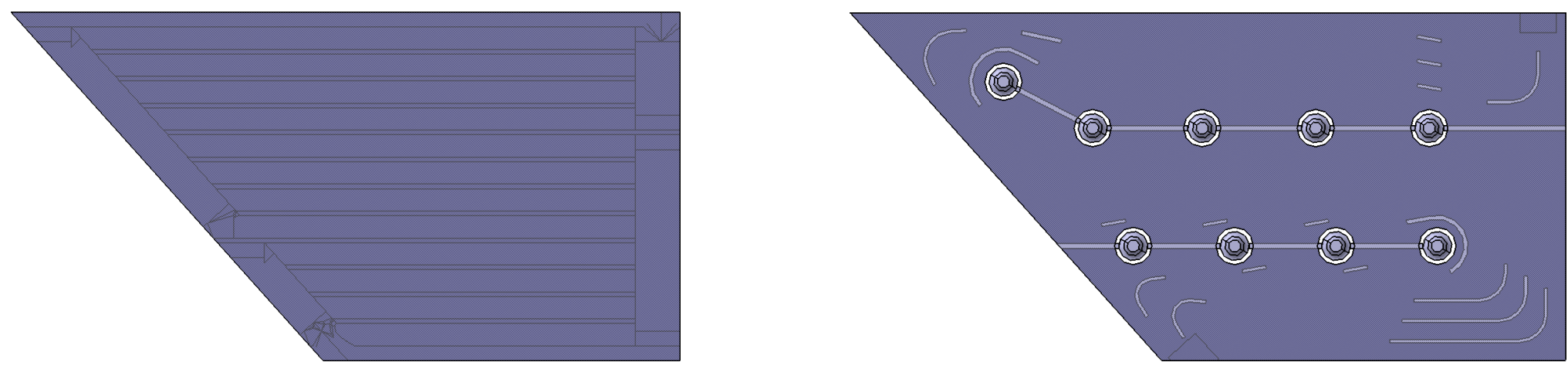

A suited vacuum chamber is going to be built for outgassing measurements of large prototypes. 


\section{Double wall prototype and outgassing - 2}
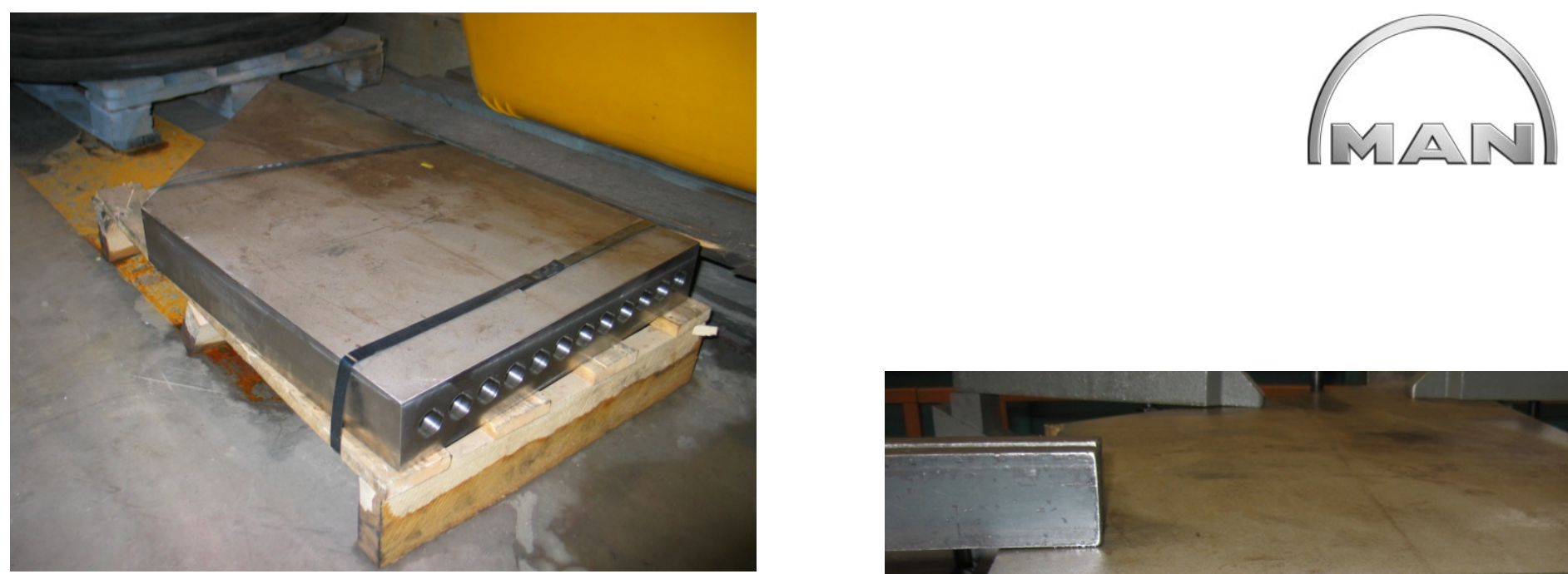

MAN DWE Apparatebau

Deggendorf www.man-dwe.de

Prototype obtained by deep hole drilling

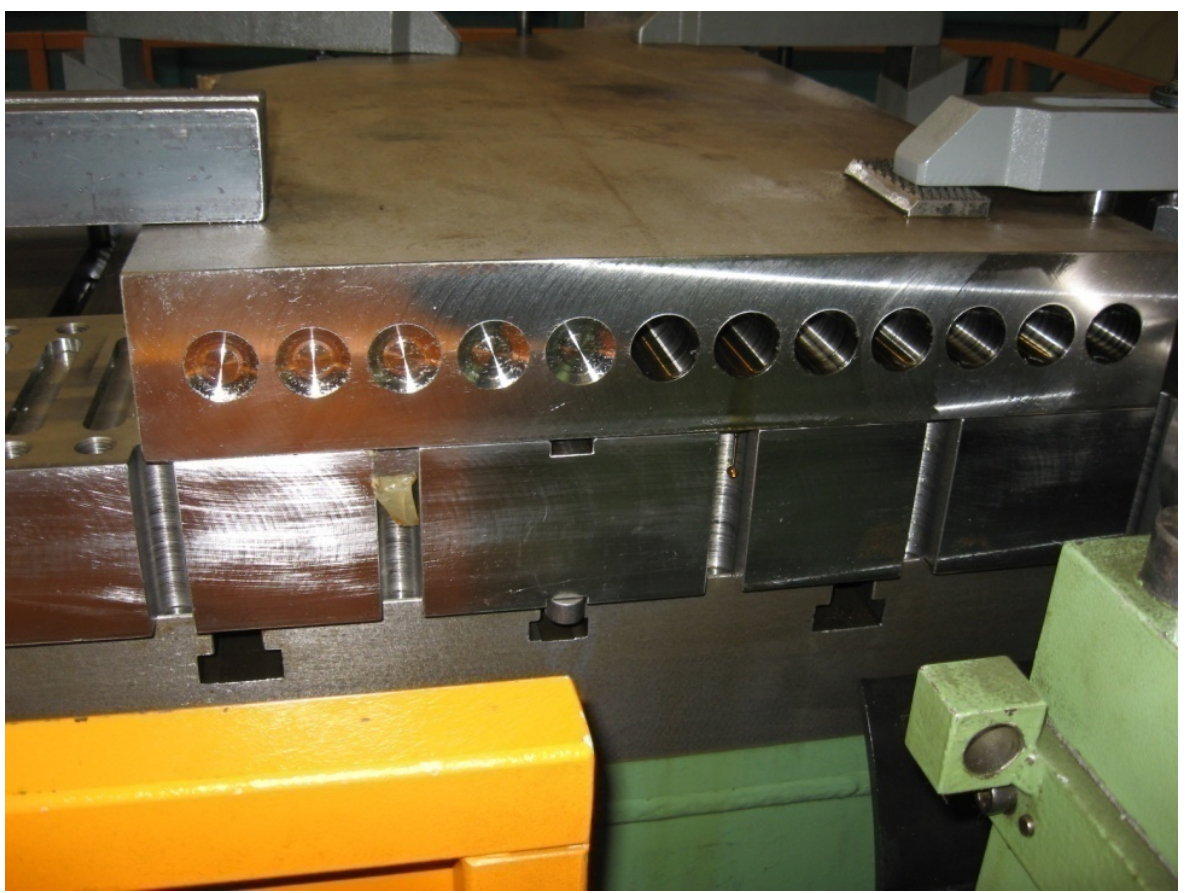




\section{Conclusions and outlook}

- Outgassing limits pertaining to VQC are defined in the ITER Vacuum Handbook.

- An experimental setup has been developed to investigate the outgassing rates of HIPed SS samples.

- Preliminary results have shown that improvements of the setup are necessary: higher sample/chamber volume ratio, load lock system...

- Outgassing measurements are also foreseen for other manufacturing routes in order to verify the compliance with the outgassing limits. 